\title{
The hidden facets of hypertension among workers
}

\author{
Anuji Gamage \\ Management, Development and Planning Unit, Ministry of Health, Sri Lanka \\ Correspondence: anujigamage@gmail.com (iD https://orcid.org/0000-0002-4713-9283 \\ DOI: https://doi.org/10.4038/jccpsl.v25i1.8213
}

Received on: 28 June 2019

Accepted on: 30 June 2019

\section{Introduction}

Hypertension is the leading risk factor for death and disability globally. It is a silent killer and a public health epidemic. Hypertension disproportionately impacts on the low- and middle-income countries predominantly in younger age groups. It is however preventable to a large extent through effective policies implemented to promote healthy behaviour and screening. In this regard, the socio-economic environment of people is well-known to play a significant role in the development of hypertension. Identifying and investing on high-risk population sub-groups that show high returns is therefore pragmatic for reducing the future burden of hypertension. The workplace is an ideal setting for such initiatives, as work-related health problems result in poor productivity and economic loss. On the other, a healthy employee adds money, positivity and productivity to the organization and country. Hence, it is a vital investment, and such investments should be made based on evidence available.

\section{Hypertension and occupation}

Hypertension contributes to 7.6 million premature deaths accounting for $13.5 \%$ of the global total as well as to 92 million disability-adjusted life years (DALYs) (1-2). As a major risk factor, it contributes to $54 \%$ of stroke and $47 \%$ of ischaemic heart disease worldwide. The global prevalence of hypertension is expected to rise by $30 \%$ during $2000-2025$, with 560 million new cases added to the existing burden (3). It disproportionately affects low- and middle-income countries; two-thirds of those with hypertension are in these countries (4). Sri Lanka is not spared, with the prevalence of hypertension steadily rising, causing a significant burden across all socio-demographic subgroups. A study conducted in 1990-1991 among 975 middle-aged males aged 35-59 years in the Central Province of Sri Lanka reported a prevalence of only $16.9 \%$ (5), which had shown to increase in the subsequent decades (6-8), highlighting the need to take immediate measures to prevent the escalating burden of hypertension.

The non-modifiable risk factors of hypertension are age, sex, and genetics, while the modifiable behavioural risk factors include unhealthy dietary habits, high salt content in the diet, alcohol consumption, smoking, sedentary lifestyle, obesity and stress (9). A crucial determinant of these behavioural risk factors is the socio-economic status (SES) of adults, which is indicated by their educational attainment, income and occupational category (10-11). In concurrence, social inequalities are identified as an important determinant of diseases (12), implying that health is determined mostly by one's living and working conditions. This is highly relevant with regard to hypertension, which acts as the single largest cause of morbidity and mortality in the working population. Depending on the nature of their work and work commitments, the risk factors of hypertension are shown to accrue over time. The classic Whitehall Study involving a cohort 18,000 of male civil servants aged 20-64 years has shown that the social gradient of workers based on their seniority/ occupation affects the morbidity and mortality in a wide range of diseases (13). 
Although the relationship between sedentary occupation and hypertension is well-established, influence of the social gradient in occupation on the prevalence and associated factors of hypertension is not studied in detail in Sri Lanka. To bridge this knowledge gap, a study was designed to explore the 'hidden facets of hypertension' to provide evidence for initiating interventions to improve work conditions that have become challenging in many ways. The study was conducted among sedentary workers aged $30-60$ years recruited into two groups: senior officers (SOs) and managerial assistants (MAs) working for more than one year in 23 public administrative offices in the district of Colombo, Sri Lanka. The SO group comprised those employed as administrative secretaries, director general, commissioner, government agent, directors and their assistants, while the MA group comprised those working as clerks, stenographers, typists, bookkeepers, storekeepers and shroff. The study population that was recruited and sampling done are given in Figure 1.

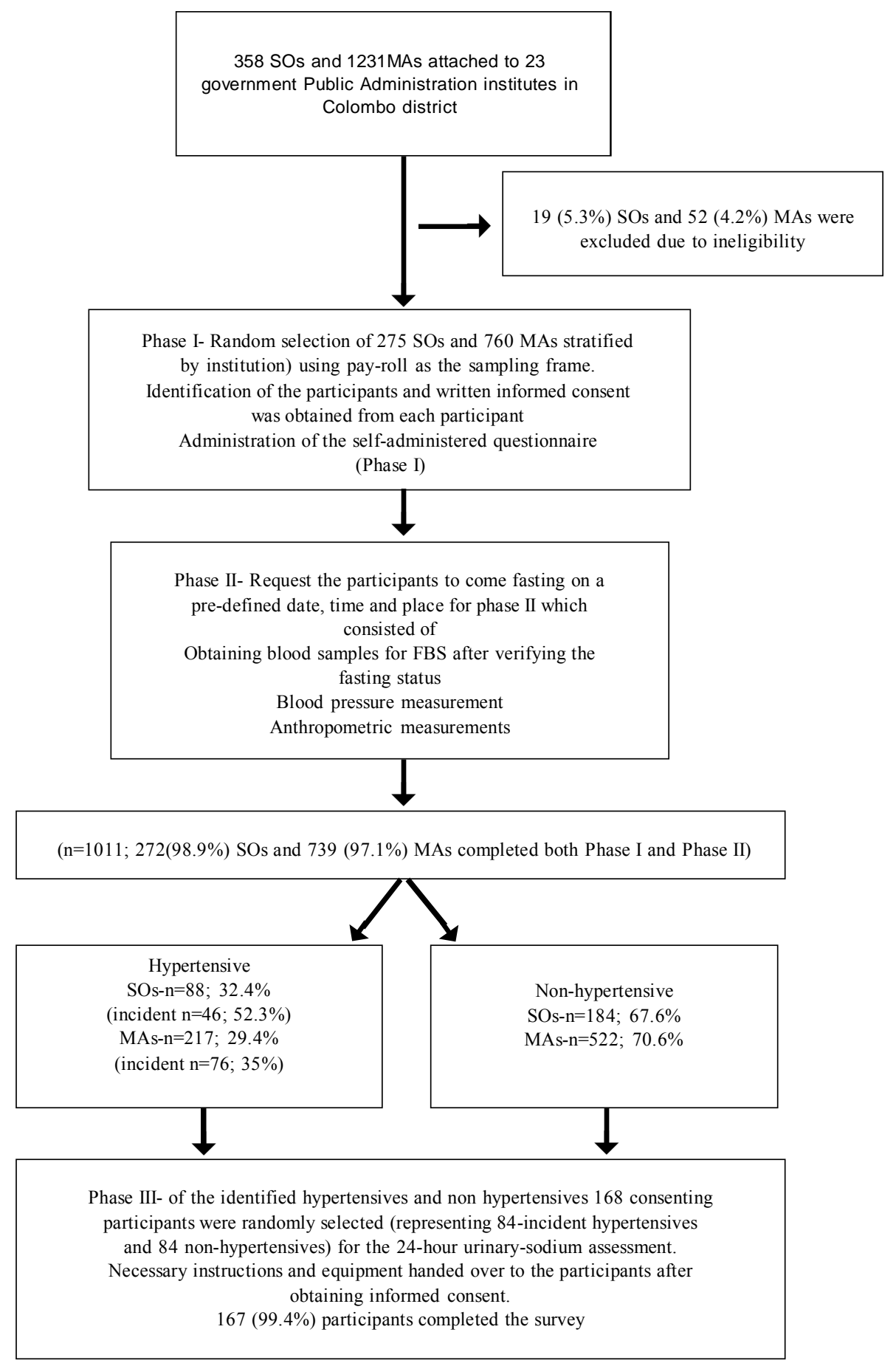

Figure 1. Flow diagram to illustrate the recruitment of the sample 


\section{Prevalence of hypertension}

The study revealed that the age- and sex-adjusted prevalence of hypertension was almost equal among SOs $(32.9 \%$; $95 \% \mathrm{CI}=27.4,38.6)$ and MAs $(33.01 \%$; 95\% CI $=29.6,36.4$ ) (Table 1) (14).

\section{Table 1. Prevalence of hypertension} in the sample

\begin{tabular}{lrrrr}
\hline $\begin{array}{l}\text { Classification of } \\
\text { hypertension }\end{array}$ & $\begin{array}{r}\text { Senior } \\
\text { officers } \\
(\mathbf{n = 2 7 2})\end{array}$ & $\begin{array}{c}\text { Managerial } \\
\text { assistants } \\
(\mathbf{n}=\mathbf{7 3 9})\end{array}$ \\
\cline { 2 - 5 } & $\begin{array}{r}\text { No. } \\
\text { \% }\end{array}$ & \multicolumn{2}{c}{ No. } & \% \\
\hline Normal & 173 & 63.6 & 469 & 63.5 \\
Pre-hypertension & 11 & 4.0 & 53 & 7.2 \\
Hypertension under control & 24 & 8.8 & 49 & 6.6 \\
Hypertension - Stage 1 & 58 & 21.3 & 147 & 19.9 \\
Hypertension - Stage 2 & 4 & 1.5 & 7 & 1.0 \\
Isolated systolic hypertension* & 2 & 0.8 & 14 & 1.8 \\
\hline Total & $\mathbf{2 7 2}$ & $\mathbf{1 0 0 . 0}$ & $\mathbf{7 3 9}$ & $\mathbf{1 0 0 . 0}$
\end{tabular}

${ }^{*}$ Systolic BP $\geq 140 \mathrm{mmHg}$ and diastolic $<90 \mathrm{mmHg}$

The 'Rule of Halves' indicates that $50 \%$ of the hypertensive cases are undetected; $50 \%$ of those detected are not treated, and $50 \%$ of those treated are not controlled (15). In support, $17 \%$ and $15 \%$ of the SOs and MAs in the study were newly diagnosed; and of those detected, $13 \%$ and $15 \%$ were on treatment for hypertension; and of those treated, $8.8 \%$ and $6.6 \%$ were currently on treatment. The findings highlight the undetected, untreated and uncontrolled cases existing among sedentary workers in Sri Lanka, who should be provided with education and screening for hypertension at workplaces.

\section{Risk factors of hypertension}

Evidence suggests that hypertension in almost $50 \%$ is attributed to an unhealthy diet; $30 \%$ to increased salt consumption; $20 \%$ to low fruit and vegetable consumption; $20 \%$ to physical inactivity; and $30 \%$ to obesity (4).

\section{- Diet and hypertension}

A meta-analysis of cohort studies reports that increased consumption of fruits and vegetables from less than three to more than five servings per day is related to a $17 \%$ reduction in the coronary heart disease (CHD) risk factors including hypertension (16-17). This supports the WHO recommendation on five or more servings of fruits and/or vegetables per day for better health (16-17).

In the present study, $52 \%$ of the SOs were not consuming a diet in the recommended amount, compared to $39 \%$ among the MAs. This imparted a significant risk among MAs $(\mathrm{OR}=2.8 ; 95 \% \mathrm{CI}=1.4,5.5)$ but not among the SOs. Further, energy intake was significantly higher among hypertensives compared to non-hypertensives among both the SOs (2335.3 versus $2049.7 \mathrm{kcal})$ and MAs $(2398.1$ versus $2226.0 \mathrm{kcal})$. In workplaces, adopting a healthy canteen policy where healthier options are available and affordable would allow employees to make healthy choices.

\section{- Salt and hypertension}

High dietary sodium intake is a known determinant of hypertension, premature death and disability. Although evidence further suggests obesity and physical inactivity as essential risk factors for the development of hypertension, the evidence for the

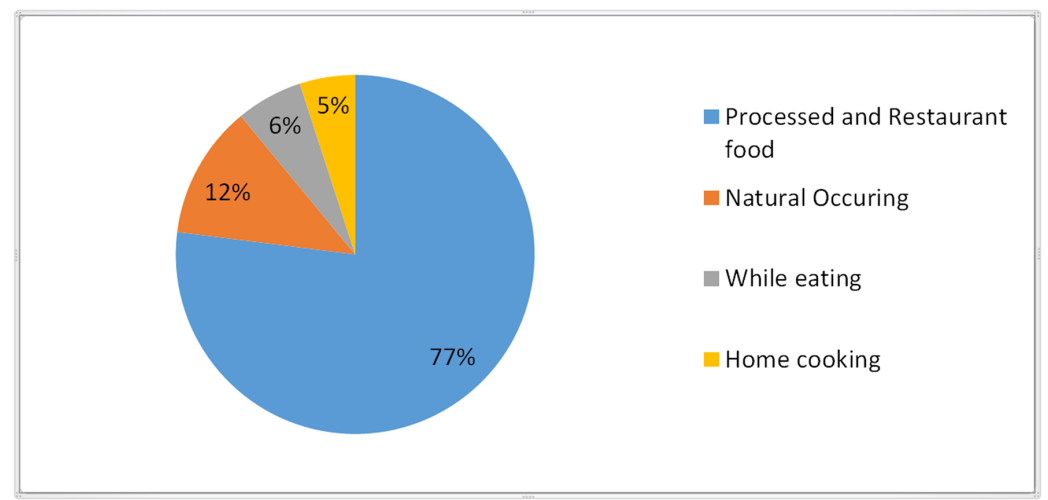

Figure 2. Dietary sodium sources in developed countries Source: Labarthe, 2011 (20) 
effect of salt on blood pressure is stronger than that of any other dietary and behavioural factor (18).

In the developed world, the sources of salt in the diet are $77 \%$ from pre-packed, processed and restaurant food, $12 \%$ from natural content of food and $11 \%$ from salt referred to as 'conscious' salt which is added at the table and during cooking (Figure 2). In contrast, countries with developing economies have diverse dietary practices with a significant amount of salt being added during the preparation of meals (19). Also, due to exposure to the globalizing food industry, these communities are exposed to high salt in processed food as well. Therefore, evidence should be further generated to identify the major sources of dietary salt to reduce the salt content of high salt containing food.

Although the recommended daily salt intake for a healthy adult is less than $5 \mathrm{~g} /$ day, a recent study that estimated the global, regional and national sodium intake in adults reported that the global mean intake was equivalent to $10.06(9.88-10.21) \mathrm{g} /$ day of salt, which was nearly twice the WHO recommended limit of $5 \mathrm{~g} /$ day. The Asian regions had the highest intakes, in which South East Asia reported a daily salt $(\mathrm{NaCl})$ intake of $12.21 \mathrm{~g} /$ day $(21)$.

In the present study, the mean salt intake among SOs and MAs was $10.84(\mathrm{SD}=4.9)$ and 11.33 $(\mathrm{SD}=5.5) \mathrm{g} /$ day respectively. This evidence confirms the findings of previous studies. After adjusting for confounding factors, a $100 \mathrm{mmol}$ increase in sodium was associated with an average increase of $3.1(95 \%$ $\mathrm{CI}=2.0,4.2) \mathrm{mmHg}$ in systolic blood pressure (SBP) and $1.8(95 \% \mathrm{CI}=0.89,2.6) \mathrm{mmHg}$ in diastolic blood pressure (DBP) (22). An average $5 \mathrm{mmHg}$ reduction in BP will be achieved for every $6 \mathrm{~g} /$ day reduction in salt. Accordingly, it can be estimated that a populationwide reduction of $6 \mathrm{~g} /$ day will result in a $24 \%$ reduction of deaths due to stroke and $18 \%$ reduction in deaths from CHD or avoidance of some 2.5 million deaths worldwide every year. A population-wide reduction in SBP of $2 \mathrm{mmHg}$ by preventive measures such as salt reduction has been predicted to lower the stroke mortality by $10 \%$ and mortality due to ischaemic heart disease or other vascular cause by approximately $7 \%$ in middle-aged populations (23). Therefore, the WHO has recognized salt reduction as one of the 'best buys,' as it is one of the most cost-effective and feasible approaches to prevent noncommunicable diseases (NCDs), with the recommendation to reduce dietary salt by $30 \%$ (24). This evidence should be utilized for the implementation of initiatives to reduce dietary salt as a measure to reduce premature deaths due to NCDs among the working population.

\section{- Physical inactivity and hypertension}

There is compelling evidence that physical inactivity is responsible for a large proportion of NCDs. It is estimated that approximately $9 \%$ of premature mortality $(5.1 \% ; 12.5 \%)$ or more than 5.3 of the 57 million deaths are attributable to physical inactivity (25-26). Occupation related activities represent the greatest portion of the daily time for most workers before retirement.

In the present study, socio-economic variations in relation to physical inactivity were observed (58.1\% among SOs and 30.6\% among MAs) (Figure 3). Of the diagnosed hypertensives, $44.7 \%$ and $49.4 \%$ reported low and moderate physical activity levels; and 35.9\% and $57.5 \%$ among the non-hypertensives. After adjusting for potential confounding factors, being physically inactive imparted a significant risk for hypertension $(\mathrm{OR}=1.33 ; 95 \% \mathrm{CI}=1.07,1.65)$, indicating that physical inactivity increases the risk of hypertension by $30 \%$ (27). Despite the current knowledge of physical activity promoting the health of an individual, the practices among sedentary workers are different. It was shown in the study that employees spend a considerable amount of time traveling to work. Majority travelled over $15 \mathrm{~km}$ to work, which is a considerable amount of time of being seated, which could be a contributory factor. It should be noted that reported physical inactivity levels are likely to be an underestimate of the true burden attributable to inactive lifestyles.

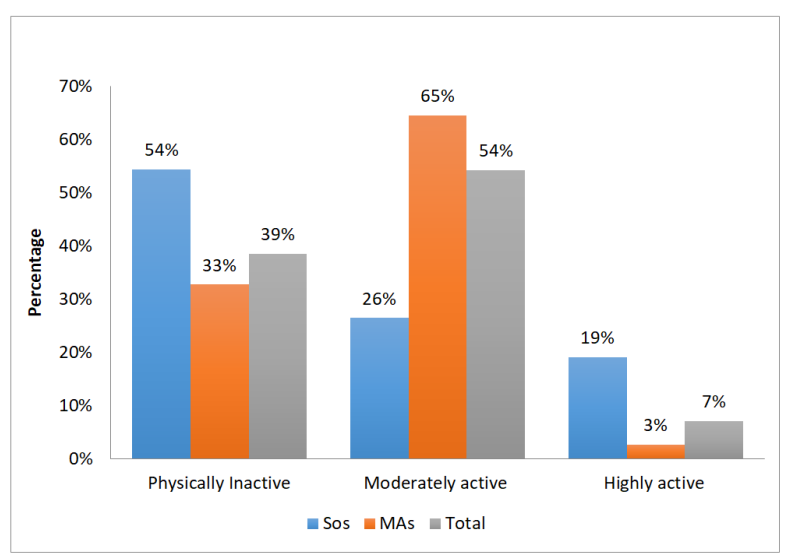

Figure 3. Physical activity levels in the sample 


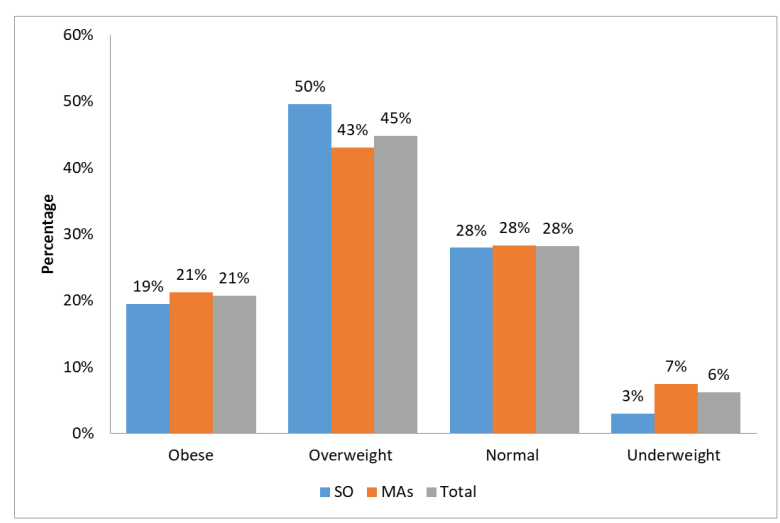

Figure 4. Prevalence of overweight and obesity in the sample

\section{- Overweight/ obesity and hypertension}

Mohan et al. (28) reported that overweight and obesity increase the risk of hypertension by $1.72(95 \%$ $\mathrm{CI}=1.32,2.26)$ and $2.37(95 \% \mathrm{CI}=1.87,2.99)$, respectively. It is alarming, since the current evidence suggests that among the overweight and obese subjects, CVD risk is not significantly increased unless hypertension is present (29).

As seen in Figure 4, 19\% and $50 \%$ of the SOs and $21 \%$ and $43 \%$ of the MAs were obese or overweight. The already established association between body weight and hypertension was observed in the present study too. Overweight and obesity were significantly associated with hypertension among SOs and MAs $(\mathrm{OR}=2.02 ; 95 \% \mathrm{CI}=1.35,3.02)$.

Findings suggest that the majority of the study population consumes an unhealthy diet, are physically inactive and obese/ overweight. Obesity results from physical inactivity, changing work conditions, eating patterns, portion sizes and the built environment. Hence, appropriate preventive measures should be taken to prevent the impact of the detrimental effects of the above on employee's health.

\section{- Stress and hypertension}

Numerous studies have explored whether the increased risk of CVD because of job stress is mediated through hypertension. Specifically, studies of job stress had indicated significant positive associations with work-related hypertension (30). During work hours, systolic BP in men facing job stress is typically $4-8$ $\mathrm{mmHg}$ higher than those without job stress and

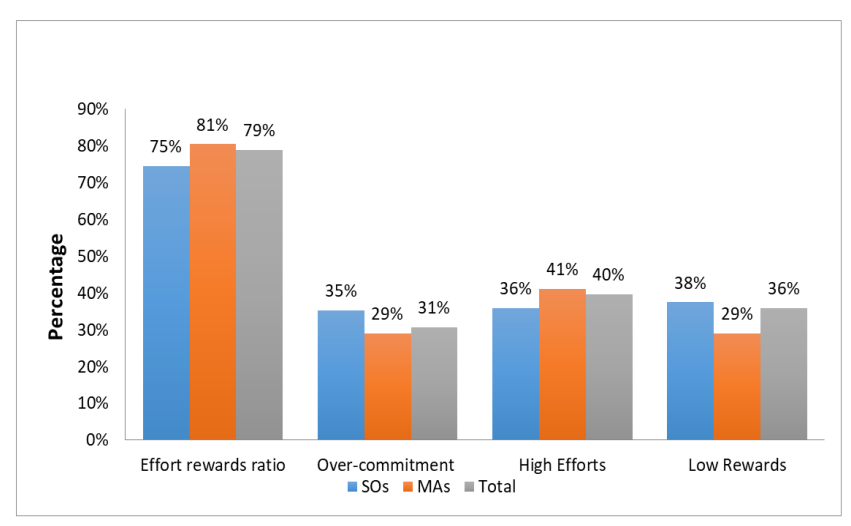

Figure 5. Prevalence of occupational stress in the sample

suggests that early detection and preventive strategies would reduce job stress (31).

The Whitehall II Study reports a significant effect of job stress measured using Efforts-Rewards-Imbalance (ERI) model on CHD incidence (32). Similarly, job stress assessed using ERI model validated for administrators in Sri Lanka (33) reported that the prevalence of hypertension among employees having ERI ratio was above $75 \%$ for SOs and MAs (Figure 5) (14). Among SOs, the job stress as measured by high ERI ( $\mathrm{OR}=2.8 ; 95 \% \mathrm{CI}=1.1,7.4)$, over-commitment $(\mathrm{OR}=2.5 ; 95 \% \mathrm{CI}=1.1,5.6)$ and high efforts $(\mathrm{OR}=2.5 ; 95 \% \mathrm{CI}=1.2,5.3)$ increased the risk of hypertension. Among the MAs, the job stress as measured by high efforts $(\mathrm{OR}=3.02 ; 95 \% \mathrm{CI}=1.9,4.8)$ was significantly associated with hypertension (14).

\section{Economic impact of hypertension}

Another facet that was looked into was the economic impact due to hypertension. Chronic diseases such as hypertension deprive individuals of their health and productive potential. The burden of chronic diseases may invariably challenge household income and savings and compete with investment activities. The socio-economic burden is two-fold. The direct impact due to the patient having to bear the cost for medication, investigations and lost earnings and the indirect impact to the country via loss of productivity due to days off from work, absenteeism and presenteeism.

Considering the direct household cost for outpatient care (OPD), the total mean cost was highest 
for obtaining treatment from consulting a physician among both SOs (Rs.5554.98) and MAs (Rs.5357.21), while it was lowest for consulting a general practitioner among both SOs (Rs.2229.07) and MAs (Rs.2992.08). Of the total OPD cost, the highest mean cost was for investigations at all three different types of consultations. The hospital admission cost to a government institution for treatment of hypertension or a related complication (Rs.12560.00) and investigation (Rs. 7741.40) was lower than the cost incurred in the private sector admission (Rs.138785.00) and investigation (Rs.68589.36).

The production loss (GDP) is the loss to the society owing to an employee being sick and loss of income to the family if an employee is removed from the workforce due to death and disability. Productivity related costs are much crucial from an employer's perspective and also would be helpful in policy debates and decision making. The estimated GDP loss due to sickness absenteeism to the government was Rs.210,513.81 for SOs $(\mathrm{n}=34)$ due to their taking 78.5 days off and Rs.194,787.27 for the Mas ( $\mathrm{n}=95)$ due to taking 268 days off. In estimating the impact on GDP in this study, only the medical and casual leave was taken into account. However, the losses due to presenteeism were not accounted for. Presenteeism is an employee on the job, but because of illness or related complications, does not adequately perform, leading to less productivity. It is reported that presenteeism accounts for a greater portion of productivity loss (34). The estimated economic impact due to lost earnings of a male and female SOs leaving the workforce early at the age of 50 years when the retirement age is 60 years was Rs.6,643,906.73 and Rs.6,989,780.60, respectively, while the economic impact due to lost earnings for a male and female among the MA was Rs.3,013,023.00 and Rs.3,178,862.85 respectively.

The cost of inaction is high. The government will have to bear the brunt of the cost of pension, the cost of an employee replacing this worker, to which will be added the cost of recruiting and training the new worker, and possible productivity losses that will be incurred due to the new worker being less experienced.

\section{Worksite health promotion}

The public health sector in Sri Lanka has both the challenge and the opportunity in addressing populationwide hypertension through prevention and control, for which evidence-based programs are mandatory. To assess the current situation, 23 administrative institutions were studied to see if they were health promotive settings. $26 \%$ of the SOs and $33.8 \%$ MAs identified the workplace as a health promoting work setting. Interestingly, $27.7 \%$ and $37 \%$ non-hypertensive SOs and MAs were from a health promotive work setting, respectively. After adjusting for confounding effects, health promotive work setting was significantly and negatively associated with hypertension among SOs $(\mathrm{OR}=0.37 ; 95 \% \mathrm{CI}=0.17,0.79)$ and $\mathrm{MAs}(\mathrm{OR}=0.48$; $95 \% \mathrm{CI}=0.28,0.81)(35)$. Considering workplace as a health promotional setting is essential to improve the work environment to be conducive to prevent unhealthy behavioural practices.

Most individuals with hypertension are unaware that their BP is high. A large proportion of those who are aware that their BP is high remain untreated and, even when treated, a large proportion still have suboptimally controlled BP. Effective lifestyle and drug treatments are available that could control hypertension in most individuals. Worksite interventions can include a wide variety of health-promotion activities because employees spend a large portion of their awake hours at work. "Health behaviour and health outcomes are products of their unique environments." The working environment should support a healthy choice.

The current study showed that the prevalence of hypertension and associated risk factors vary depending on the job category, which acts as a social determinant. This is the attributable risk; the portion of disease rate attributable to the exposure and therefore could be prevented. Once exposed to the risk factor/s however, the magnitude of an exposure and disease remains the same among the categories.

\section{Nudging to be healthy - The way forward}

It should be kept in mind that habits that took years to build cannot be changed overnight. It needs sustainable efforts from all concerned. Choice architecture is a solution to change. Choice architecture is a configuration for how the choices are presented and Nudge Theory is about encouraging, or nudging, people to make healthier lifestyle choices without being 'nannied' and without losing freedom of choice (36). The choice architecture heavily influences humans. A nudge is a carefully defined choice architecture which 
gently pushes people toward a decision that will benefit them while preserving the full choices for people who wish to go their own way. Rather than trying to overtly 'change' people's behaviour, the idea is to subtly direct people down a particular path by altering their environment. The core of the nudge, concept is making healthier options more feasible, accessible, and appealing. Making the choices available is our task. Every setting is a health setting. Worksite health promotion activities should include regular periodic screening and surveillance, provision of healthy opportunities like a healthy diet, physical activity, mental health and wellbeing, and policy commitment. The actions should be continued with inbuilt monitoring and evaluation.

\section{Acknowledgment}

The author would like to especially thank Prof. Rohini De A Seneviratne, Senior Professor of Community Medicine, General Sir John Kotelawala Defence University, Sri Lanka for supporting with professional advice and guidance concerning all aspects of the research and dissemination of findings.

\section{References}

1. Lawes CM, Vander Hoorn S, Rodgers A. Global burden of blood pressure related disease 2001. The Lancet 2008; 371(9623): 1513-1518.

2. Poulter NR, Prabhakaran D, Caulfield M. Hypertension. The Lancet 2015; 386(9995): 801-812.

3. Kearney PM, Whelton M, Reynolds K, Muntner P, Whelton PK, He J. Global burden of hypertension: analysis of worldwide data. The Lancet. 2005; 365(9455): 217-223.

4. Campbell NRC, Lackland DT, Niebylski ML, the World Hypertension League and International Society of Hypertension Executive Committees. High blood pressure: why prevention and control are urgent and important - a 2014 fact sheet from the World Hypertension League and the International Society of Hypertension. The Journal of Clinical Hypertension 2014; 16(8):551-553.

5. Mendis S \& Ekanayake EMTKB. Prevalence of coronary heart disease and cardiovascular risk factors in middle aged males in a define population in Sri Lanka. International Journal of Cardiology. 1994; 46(2): 135-142.

6. Wijewardene K MM, Mendis S, Fernando DS, Kulathilaka T, Weerasekara D, Uluwitta P. Prevalence of hypertension, diabetes and obesity: baseline findings of a population-based survey in four provinces in Sri Lanka. Ceylon Medical Journal 2005; 50(2): 62-70.

7. Kasturiratne A, Pinidiyapathirage MJ, Pathmeswaran A, Kato N, Wickremasinghe AR, de Silva HJ. Epidemiology of hypertension in an urban population of Sri Lanka. The Ceylon Medical Journal 2011; 56(Supplement 1): S60.

8. Katulanda P, Ranasinghe P, Jayawardena R, Constantine GR, Sheriff MHR, Matthews DR. The prevalence, predictors and associations of hypertension in Sri Lanka: a cross-sectional population based national survey. Clinical \& Experimental Hypertension 2014; 36(7): 484-491.

9. WHO. Preventing chronic diseases: a vital investment. Geneva: World Health Organization, 2005.

10. Ji C, Kandala N-B, Cappuccio FP. Spatial variation of salt intake in Britain and association with socioeconomic status. BMJ Open 2013; 3(1).

11. Marmot MG. Understanding social inequalities in health. Perspectives in Biology and Medicine 2003; 46(3 Suppl): S9-23.

12. Marmot M. Social determinants of health inequalities. The Lancet 2005; 365(9464): 1099-1104.

13. Marmot MG, Bosma H, Hemingway H, Brunner E, Stansfeld S. Contribution of job control and other risk factors to social variations in coronary heart disease incidence. The Lancet 1997; 350(9073): 235-239.

14. Gamage AU \& Seneviratne R de A. Perceived job stress and presence of hypertension among administrative officers in Sri Lanka. Asia-Pacific Journal of Public Health 2016; 28(1 Suppl): S41-52.

15. Faizi N, Ahmad A, Khalique N, Shah MS, Khan MS, Maroof M. Existence of Rule of Halves in hypertension: an exploratory analysis in an Indian village. Materia Sociomedica 2016; 28(2): 95-98.

16. WHO. The Atlas of Heart Disease and Stroke. Geneva: World Health Organization, 2003.

17. WHO. A global brief on hypertension; silent killer, global public health crisis. Geneva: World Health Organization, 2013.

18. He F \& MacGregor G. A comprehensive review on salt and health and current experience of worldwide salt reduction programmes. Journal of Human Hypertension 2009; 23(6): 363-384.

19. Mohan S \& Prabhakaran D. Review of salt and health: situation in South-East Asia Region. Background Paper for the Expert Meeting on Population. 
Sodium reduction strategies for prevention and control of noncommunicable diseases in the SouthEast Asia Region. New Delhi: World Health Organization, 2012.

20. Labarthe DR. Epidemiology and prevention of cardiovascular diseases: a global challenge. Massachusetts: Jones \& Bartlett Publishers, 2011.

21. Powles J, Fahimi S, Micha R, Khatibzadeh S, Shi P, Ezzati M, et al. Global, regional and national sodium intakes in 1990 and 2010: a systematic analysis of 24 $\mathrm{h}$ urinary sodium excretion and dietary surveys worldwide. BMJ Open 2013; 3(12).

22. Gamage AU, Seneviratne R de A, Hanna FS. Salt intake, blood pressure, and socioeconomic disparities among government employees in Sri Lanka: a crosssectional study. Journal of Public Health Policy 2017; 38(3): 327-344.

23. Lewington S, Clarke R, Qizilbash N, Peto R, Collins R. Prospective Studies Collaboration. Age-specific relevance of usual blood pressure to vascular mortality: a meta-analysis of individual data for one million adults in 61 prospective studies. The Lancet 2002; 360(9349): 1903-1913.

24. WHO. Global Status Report on Noncommunicable Diseases 2010. Geneva: World Health Organization, 2010.

25. Lee IM, Shiroma EJ, Lobelo F, Puska P, Blair SN, Katzmarzyk PT, Lancet Physical Activity Series Working Group. Effect of physical inactivity on major non-communicable diseases worldwide: an analysis of burden of disease and life expectancy. The Lancet 2012;380(9838): 219-229.

26. Kohl HW, Craig CL, Lambert EV, Inoue S, Alkandari JR, Leetongin G, et al. The pandemic of physical inactivity: global action for public health. The Lancet 2012;380(9838): 294-305.

27. Gamage A, Seneviratne R, Hanna F. Physical inactivity as a predictor of hypertension among employees in Sri Lanka: a cross-sectional study. Journal of Hypertension 2016; 34: e480.
28. Mohan V, Farooq S, Datta M, Deepa R. Prevalence, awareness and control of hypertension in Chennai The Chennai Urban Rural Epidemiology Study (CURES - 52). Journal of the Association of Physicians of India 2007; 55: 848.

29. Narkiewicz K. Obesity and hypertension - the issue is more complex than we thought. Nephrology Dialysis Transplantation 2005; 21(2): 264-267.

30. Landsbergis PA, Schnall PL, Warren K, Pickering TG, Schwartz JE. Association between ambulatory blood pressure and alternative formulations of job strain. Scandinavian Journal of Work, Environment \& Health 1994; 20(5): 349-363.

31. Vrijkotte TG, van Doornen LJ, de Geus EJ. Effects of work stress on ambulatory blood pressure, heart rate, and heart rate variability. Hypertension. 2000; 35(4): 880-886.

32. Kuper H, Singh-Manoux A, Siegrist J, Marmot M. When reciprocity fails effort-reward imbalance in relation to coronary heart disease and health functioning within the Whitehall II study. Occupational and Environmental Medicine. 2002; 59(11): 777-784.

33. Gamage A, Seneviratne R de A, Hanna F. The EffortReward Imbalance Questionnaire in Sinhalese: translation, validation and psychometric properties in administrators. Psychological Studies 2016; 61(2): 96-102.

34. Kaan, 2005. Investing in people: financial impact of human resources initiatives ( $2^{\text {nd }}$ edition). New Jersey: FT Press, 2011.

35. Gamage A, Seneviratne R, Hanna F. Worksite Health Promotion Score: to assess a health promotional worker setting. Journal of Hypertension 2016; 34 : e274.

36. Thaler RHaSCR. Nudge: improving decisions about health, wealth and happiness. New Haven: Yale University Press, 2008. 